Table 1. a) Demographics and Characteristics at Baseline (week 0 ) and b) Descriptive observed data for the individual components of the ASAS response criteria at week 52 , mean (SD)

\begin{tabular}{|c|c|c|}
\hline \multirow[t]{2}{*}{ a) } & \multicolumn{2}{|l|}{ IXEQ4W } \\
\hline & $\begin{array}{c}\text { Patients sustaining an ASAS20 } \\
\text { but not reaching an ASAS40 } \\
\text { response at week } 52 \\
(n=12)\end{array}$ & $\begin{array}{c}\text { Patients achieving an } \\
\text { ASAS40 response at } \\
\text { week } 52 \\
(n=12)\end{array}$ \\
\hline Age, years & $47.3(13.3)$ & $49.6(12.3)$ \\
\hline $\begin{array}{l}\text { Duration of symptoms since } \\
\text { axSpA onset, years }\end{array}$ & $16.4(9.2)$ & $18.6(12.6)$ \\
\hline HLA B27 positive, n (\%) & $12(100)$ & $9(75)$ \\
\hline Current tobacco use, $n(\%)$ & $4(33.3)$ & $1(8.3)$ \\
\hline ASDAS Score & $4.0(1.0)$ & $4.2(1.1)$ \\
\hline BASDAI Score & $7.4(1.2)$ & $7.8(1.7)$ \\
\hline Serum CRP concentration (mg/L) & $23.0(47.1)$ & $28.0(66.0)$ \\
\hline $\begin{array}{l}\text { Spinal Pain due to Ankylosing } \\
\text { Spondylitis (NRS) }\end{array}$ & $8.2(0.8)$ & $8.5(1.6)$ \\
\hline $\begin{array}{l}\text { Patient Global Assessment of } \\
\text { Disease Activity (NRS) }\end{array}$ & $7.8(1.3)$ & $8.6(1.2)$ \\
\hline BASFI & $7.1(1.4)$ & $7.4(2.3)$ \\
\hline $\begin{array}{l}\text { BASDAI stiffness score } \\
\text { b) }\end{array}$ & $\begin{array}{l}7.1(1.5) \\
\text { IXEQ4W }\end{array}$ & $7.6(2.2)$ \\
\hline $\begin{array}{l}\text { Patient Global Assessment of } \\
\text { Disease Activity (NRS) }\end{array}$ & $5.5(1)$ & $3.2(1.3)$ \\
\hline $\begin{array}{l}\text { Spinal Pain due to Ankylosing } \\
\text { Spondylitis (NRS) }\end{array}$ & $5.6(1)$ & $3(1.9)$ \\
\hline BASFI & $5.0(1.5)$ & $3.7(2.1)$ \\
\hline BASDAl stiffness score & $4.1(1.4)$ & $3.4(2.3)$ \\
\hline
\end{tabular}

Values are mean $(\mathrm{SD})$ unless stated otherwiseASAS= Assessment of SpondyloArthritis International Society; ASDAS= Ankylosing Spondylitis Disease Activity Score; axSpa = axial spondyloarthritis; BASDAI= Bath Ankylosing Spondylitis Disease Activity Index; BASFI= Bath Ankylosing Spondylitis Functional Index; $\mathrm{CRP}=\mathrm{C}$-reactive protein; $\mathrm{HLA}=$ human leucocyte antigen; $\mathrm{NRS}=$ numeric rating scale; $\mathrm{SD}=$ standard deviation

Conclusion: For patients with r-axSpA previously exposed to TNFis and showing modest response to IXE over 16 weeks, longer exposure to IXE may be required to achieve ASAS40.

Acknowledgements: The authors would like to acknowledge Philana Fernandes, an employee of Eli Lilly, for her editorial and writing support.

Disclosure of Interests: Xenofon Baraliakos Speakers bureau: Abbvie, BMS, Chugai, Celgene, Eli Lilly, Pfizer, Galapagos, UCB, MSD, Consultant of: Abbvie, BMS, Chugai, Celgene, Eli Lilly, Pfizer, Galapagos, UCB, MSD, Grant/research support from: Abbvie, Celgene, MSD, Atul Deodhar Consultant of: AbbVie, Amgen, Boehringer Ingelheim, Bristol Myers Squibb, Celgene, Eli Lilly, Giliad, GlaxoSmith \& Kline, Janssen, Novartis, Pfizer, UCB, Grant/research support from: AbbVie, Boehringer Ingelheim, Eli Lilly, GlaxoSmith \& Kline, Novartis, Pfizer, UCB, Soyi Liu Leage Employee of: Eli Lilly, Yves Schymura Employee of: Eli Lilly, Rebecca Bolce Shareholder of: Eli Lilly, Employee of: Eli Lilly, David Sandoval Shareholder of: Eli Lilly, Employee of: Eli Lilly, Jessica A. Walsh Consultant of: AbbVie, Novartis, Eli Lilly, UCB, Amgen \& Pfizer, Grant/research support from: AbbVie, Pfizer, Merck, Joachim Sieper Speakers bureau: Abbvie, Janssen, Eli Lilly and Novartis, Consultant of: Abbvie, Janssen, Eli Lilly and Novartis.

DOI: 10.1136/annrheumdis-2021-eular.1823

\section{AB0472 DISEASE ACTIVITY AND OUTCOME IN PREGNANCIES OF PATIENTS WITH SPA - DATA FROM THE GERMAN PREGNANCY REGISTER RHEKISS}

A. Weiß ${ }^{1}$, C. Bungartz ${ }^{1}$, J. Richter ${ }^{2}$, S. Spaethling-Mestekemper ${ }^{3}$ X. Baraliakos ${ }^{4}$, P. M. Aries ${ }^{5}$, R. Fischer-Betz ${ }^{2}$, A. Strangfeld ${ }^{1}$. ${ }^{1}$ German Rheumatism Research Centre, Epidemiology Unit, Berlin, Germany; ${ }^{2}$ University Hospital Düsseldorf, Department of Rheumatology \& Hiller Research Unit, Düsseldorf, Germany; ${ }^{3}$ Rheumapraxis München-Pasing, Rheumatology, München, Germany; ${ }^{4}$ Rheumazentrum Ruhrgebiet, Rheumatology, Herne, Germany; ${ }^{5}$ Reumatologie, Rheumatology, Hamburg, Germany

Background: Spondyloarthritis ( $\mathrm{SpA})$ is a severe chronic inflammatory disease, which affects quality of life and functional status. It frequently occurs in women of childbearing age. Active disease and TNFi discontinuation at early pregnancy were found to be risk factors for flares during pregnancy (1).
Objectives: To compare disease activity during pregnancy in patients with or without bDMARD exposure at conception and during pregnancy and to assess pregnancy outcomes.

Methods: RHEKISS is a prospective longitudinal cohort study including patients with confirmed diagnose of inflammatory rheumatic disease. Preg nant patients are eligible to be enrolled until the $20^{\text {th }}$ week of gestation regardless of drug treatment. During observation, information on treatment disease and pregnancy course, and outcome is collected from rheumatologists and patients. For this analysis, pregnancies of patients with SpA were selected and stratified into three groups according to their exposure to bDMARDs.

Results: Of $140 \mathrm{SpA}$ pregnancies included, 74 (53\%) were not exposed to bDMARDs at conception (group 1), 38 (27\%) were exposed to bDMARDs at conception, but not during pregnancy (group 2) and $28(20 \%)$ were continuously exposed to bDMARDs at conception and during pregnancy (group $3)$. Certolizumab (50\%), Adalimumab (20\%), Etanercept ( $8 \%)$ and Infliximab $(8 \%)$ were the most frequently prescribed bDMARDs at beginning of pregnancy. Baseline characteristics according to treatment exposure are shown in Table 1. Frequency of flares was highest in group 2: $21 \%, 38 \%$, and $39 \%$ of patients flared during the $1^{\text {st }}, 2^{\text {nd }}$, and $3^{\text {rd }}$ trimester. These rates were $20 \%$, $25 \%$, and $21 \%$ in group 1 and $8 \%, 20 \%$, and zero in group 3 . The difference in flare rates was also mirrored in the course of physician assessed global disease activity (Figure 1). Whereas patients in group 1 seemed to have a quite stable disease activity during pregnancy, those who were in group 2 had an increasing activity of disease during pregnancy with an even higher increase of disease activity after giving birth. Patients in group 3 had the lowest disease activity.

Of 137 singleton pregnancies, 130 (95\%) ended in live birth. Of 6 spontaneous abortions 2 were in every of the three groups. One pregnancy in group 1 was terminated in gestational week 22 due to suspect malformation. One baby of the triple pregnancy was born and two aborted. All babies of the twin pregnancies were born healthy.

Conclusion: SpA patients treated with bDMARDs at conception are not at higher risk for adverse pregnancy outcomes. Our results in a larger patient population confirmed that discontinuation of bDMARDs after conception is associated with increased disease activity during pregnancy and after birth and a higher risk of flares.

\section{REFERENCES:}

[1] van den Brandt S et al., Arthritis Res Ther. 2017; 19(1):64.

Table 1. Baseline characteristics; numbers are $\mathbf{n}(\%)$ if not otherwise specified; * value at beginning of pregnancy: first 22 weeks after conception

\begin{tabular}{|c|c|c|c|c|}
\hline Parameter & $\begin{array}{c}\text { no bDMARD } \\
\text { at conception } \\
\text { (group 1) } \\
n=74\end{array}$ & $\begin{array}{l}\text { bDMARD at } \\
\text { conception and } \\
\text { discontinued } \\
\text { during } \\
\text { pregnancy } \\
\text { (group 2) } \\
n=38\end{array}$ & $\begin{array}{c}\text { bDMARD at } \\
\text { conception and } \\
\text { continued } \\
\text { during pregnancy } \\
\text { (group 3) } \\
n=28\end{array}$ & $\begin{array}{c}\text { Total } \\
n=140\end{array}$ \\
\hline Singleton & $72(97)$ & $37(97.4)$ & $28(100)$ & 137 (97.9) \\
\hline Twin & $1(1.4)$ & $1(2.6)$ & 0 & $2(1.4)$ \\
\hline Triple & $1(1.4)$ & 0 & 0 & $1(0.7)$ \\
\hline $\begin{array}{l}\text { New-York criteria } \\
\text { fulfilled }\end{array}$ & $21(33)$ & $17(49)$ & $10(48)$ & $48(40)$ \\
\hline $\begin{array}{l}\text { disease duration in } \\
\text { years, mean (SD) }\end{array}$ & $6.4(5.9)$ & $7(4.1)$ & $5.8(4)$ & $6.4(5.1)$ \\
\hline age $^{\star}$, mean $(S D)$ & $33.4(4.9)$ & $32.3(4)$ & $31.6(3.4)$ & $32.7(4.4)$ \\
\hline $\begin{array}{l}\text { severity of illness*: } \\
\text { asymptomatic }\end{array}$ & $4(6)$ & $0(0)$ & $3(14)$ & $7(6)$ \\
\hline mild & $31(48)$ & $6(17)$ & $4(19)$ & $41(34)$ \\
\hline moderate & $24(38)$ & $21(60)$ & $14(67)$ & $59(49)$ \\
\hline severe & $5(8)$ & $8(23)$ & 0 & $13(11)$ \\
\hline HLA-B27 positive & $41(62)$ & $24(80)$ & $15(75)$ & $80(69)$ \\
\hline $\begin{array}{l}\text { CRP in } \mathrm{mg} / \mathrm{l} \text { *, } \\
\text { mean (SD) }\end{array}$ & $6.6(8.2)$ & $5.4(8.2)$ & $5.2(4.9)$ & $6(7.6)$ \\
\hline $\mathrm{CRP}>5 \mathrm{mg} / \mathrm{I}^{*}$ & $25(41)$ & $9(30)$ & $8(35)$ & $42(37)$ \\
\hline 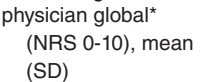 & $2.6(2)$ & $2.3(2.5)$ & $1.7(1.4)$ & $2.4(2.1)$ \\
\hline $\begin{array}{l}\text { BASDAl }^{*}(0-10) \\
\text { mean }(S D)\end{array}$ & $3.2(2)$ & $2.9(2.3)$ & $2.8(1.5)$ & $3.1(2)$ \\
\hline $\begin{array}{c}\text { patient global* (NRS } \\
0-10) \text {, mean (SD) }\end{array}$ & $3.3(2.7)$ & $3(2.8)$ & $3(2.3)$ & $3.1(2.6)$ \\
\hline
\end{tabular}




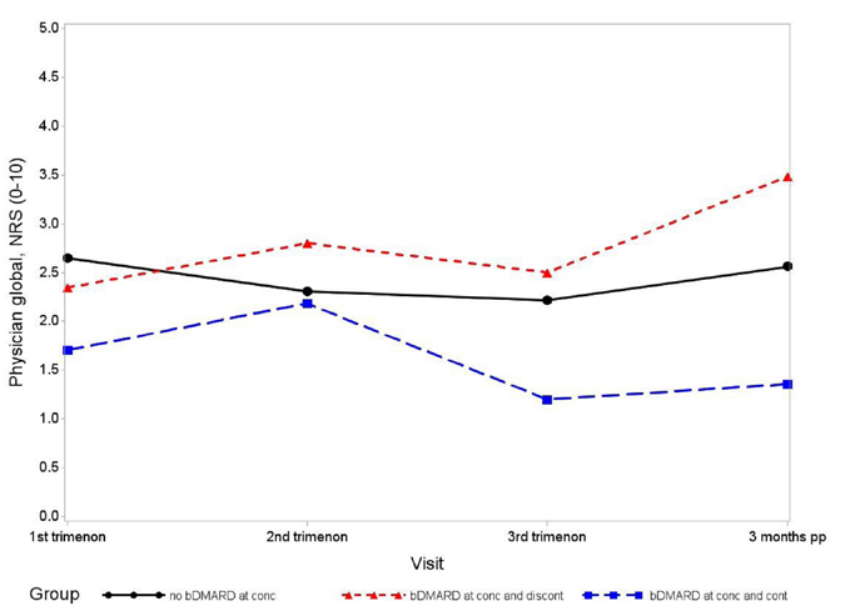

Figure 1 Course of physician assessed global disease activity

Disclosure of Interests: None declared.

DOI: 10.1136/annrheumdis-2021-eular.2087

\section{AB0473 TREATMENT OF ANKYLOSING SPONDYLITIS (AS) DURING PREGNANCY}

O. Krichevskaya ${ }^{1}$, T. Dubinina ${ }^{1}$, E. llinykh ${ }^{1}$, S. Glukhova ${ }^{1}$, A. Demina ${ }^{1}{ }^{1}$ V. A. Nasonova Research Institute of Rheumatology, Laboratory of Medical and Social Problems of Rheumatology, Moscow, Russian Federation

Background: The use of medications during pregnancy remains a challenge for both rheumatologists and patients. The lack of compelling evidence of the safety of a line of different drugs, as well as the traditional idea of the incompatibility of therapy and gestation that is common view in Russia, lead to unjustified withdrawal of drugs by both pregnant women and rheumatologists.

Objectives: to describe the frequency of drug usage in pregnant women with AS, to determine the relationship of AS activity and pregnancy complications.

Methods: 49 pregnant women with confirmed AS (modified New York criteria, 1984) were included for prospective observation. 50 pregnancies in total were traced. The average age of the patients was $31.6 \pm 4.9$ years, the duration of the disease was $134.4 \pm 85.8$ months. The visits were conducted at 10-11, 20-21, and 31-32 weeks of pregnancy. The BASDAl in the month of conception and in the trimesters of pregnancy was: $1,4[0,6 ; 3,3] ; 2,3[1,2 ; 4,4] ; 2,8[1,4$; $4,2]$ and $2,2[1,6 ; 4,0]$, respectively. 48 pregnancies ended with the birth of alive children at an average of $39 \pm 1.1$ weeks, the height of newborns $-51.6 \pm 2.1 \mathrm{~cm}$, weight-3397.3 $\pm 433.1 \mathrm{~g} .8$ (16.3\%) newborns had malformations, 7 of them - minor heart development anomalies, 1 - hydronephrosis. Pregnancy complications: early toxicosis - $18 \%$ of pregnant women, threatening of early abortion $10 \%$, threatening of late abortion- $4.1 \%$, threatening of early preterm birth $-6.3 \%$; premature birth $-3(6.3 \%)$ at $36.8 \pm 0.1$ weeks.

Results: NSAIDs. After inclusion in the study, the drug of choice was ibuprofen, which was canceled for all women no later than the 32-nd week of pregnancy. At the time of conception and in the first, second and third trimesters of pregnancy, NSAIDs were taken by $23(46 \%), 20(40 \%), 30(60 \%)$ and 21 (43.8\%) women, respectively. No effect of NSAIDs on the activity of AS was revealed.

Sulfasalazine (SS) was taken for 3 months before pregnancy by $11(22 \%)$ women, during pregnancy $-6(12 \%)$ at a dose of $1.25 \pm 0.25 \mathrm{~g}$ because of arthritis. The withdrawal of SS was not associated with the recurrence of arthritis.

Glucocorticoids (GC) at a dose of $7.5 \pm 2.5 \mathrm{mg} 3$ months before pregnancy and in the trimesters of pregnancy were taken: $1(2 \%), 4(8 \%), 8(16 \%)$ and $10(20.8 \%)$ women, of whom 1 patient had arthritis and 1 had inflammatory bowel disease. The remaining patients received GC due to the high activity of AS due to axial manifestations and the unavailability of bDMARDs) intake. Against the background of taking GC, the AS activity did not decrease: BASDAl in the 2nd and 3rd trimesters was $5.5 \pm 0.6$ and $5.8 \pm 1.3(p>0.05)$.

bDMARDs. TNF inhibitors for 3 months before pregnancy and on trimesters were received by $11(22 \%), 7(14 \%), 6(12 \%)$ and $2(4.2 \%)$ patients, of which 1 woman in the second trimester obtained firstly initiated therapy with certolizumab pegol due to the recurrence of uveitis. In those who canceled bDMARDs therapy (both independently and due to the recommendation of a rheumatologist), an increase in AS activity was noted on the eve of pregnancy; BASDAI in the month of conception and in the I, II, and III trimesters was: $2,7[0,8 ; 3,5] ; 5,1[3,1 ; 5,9] ; 5,5$ $[5 ; 6]$ and $6,7[5,3 ; 7 ; 3], p<0,05$ compared to the month of conception. Undoing the bDMARDs in the month of conception is a risk factor for high activity as
(BASDAl>4) in the second trimester (OR OF $30.4 ; 95 \% \mathrm{Cl} 1,5-612,3 ; \mathrm{p}=0.03$ ) and in the third trimester (OR A 32.7; 95\% $\mathrm{Cl} 1,6-662,2 ; \mathrm{p}=0.02$ ).

The relationship between pregnancy complications, malformations of the newborns and the used medications was not revealed.

Conclusion: NSAIDs and GC in low doses do not reduce the activity of AS. Withdrawal of TNF inhibitors on the eve of pregnancy is a predictor of high AS activity. It is necessary to increase the knowledge of rheumatologists and patients about the therapeutic possibilities during pregnancy to avoid unjustified drug withdrawal.

Disclosure of Interests: None declared.

DOI: 10.1136/annrheumdis-2021-eular.2427

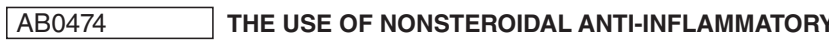 DRUGS (NSAIDS) IN WOMEN WITH ANKYLOSING SPONDYLITIS (AS) DURING PREGNANCY}

O. Krichevskaya ${ }^{1}$, T. Dubinina ${ }^{1}$, E. llinykh ${ }^{1}$, S. Glukhova ${ }^{1}$, A. Demina ${ }^{1} .{ }^{1}$ V. A. Nasonova Research Institute of Rheumatology, Laboratory of Medical and Social Problems of Rheumatology, Moscow, Russian Federation

Background: NSAIDs remain the first-line drugs in treatment of AS. During pregnancy, COX-2 non-selective NSAIDs are allowed for intake up to 32 weeks, but the question of the dose-dependent effect of NSAIDs on fetal organogenesis in the 1st trimester and on fetal kidney function and the increased risk of bleeding in childbirth when taken in the second half of pregnancy continues to be discussed. At the same time, data on the effectiveness of NSAIDs, including their low and medium doses, during pregnancy are extremely small.

Objectives: to describe the frequency of using NSAIDs during pregnancy, to determine relationship between the dose of NSAIDs, adherence to therapy with the activity of AS.

Methods: 50 pregnancies were followed in 49 pregnant women with confirmed AS (modified New York criteria, 1984). The average age of the pts was $31.6 \pm$ 4.9 years, the duration of the disease was $134.4 \pm 85.8$ months. The visits were conducted at 10-11, 20-21, and 31-32 weeks of pregnancy. The BASDAl in the month of conception and in the trimesters (trim.) of pregnancy was: $1,4[0,6$; $3,3] ; 2,3[1,2 ; 4,4] ; 2,8[1,4 ; 4,2]$ and $2,2[1,6 ; 4,0]$, respectively. The level of nocturnal back pain according to the NRS in the first, second and third trim. was: $3.2 \pm 2.0 ; 5.4 \pm 2.5$ and $5.2 \pm 2.6$, respectively. The drug of choice was ibuprofen at a maximum daily dose of $1200 \mathrm{mg}$, its withdrawal - no later than 32 weeks of pregnancy.

Adherence to NSAID therapy was defined as the ratio of the actual dose taken to the prescribed dose; an indicator of less than $80 \%$ was regarded as non-adherence to therapy. The total dose of NSAIDs was determined by the NSAID intake index (M. Dougados, 2001). The" actual daily dose" of ibuprofen was the sum of the doses of ibuprofen taken, divided by the number of actual days of taking the drug. The "average daily dose" was defined as the sum of the ibuprofen doses taken, divided by the number of days in the trimester.

Results: At the time of conception and in the first, second and third trim. of pregnancy, NSAIDs were taken $23(46 \%), 20(40 \%), 30(60 \%)$ and $21(43.8 \%)$ women, respectively. The NSAID intake index, the actual and average daily dose of ibuprofen are shown in the Table 1.

\begin{tabular}{lcccc}
\hline & $\begin{array}{c}\text { month of } \\
\text { conception }\end{array}$ & trim. 1 & trim. 2 & trim. 3 \\
\hline the actual daily dose, $\mathrm{mg}$ & - & 700 & 800 & 750 \\
& & {$[425 ; 800]$} & {$[400 ; 1000]$} & {$[400 ; 1200]$} \\
the average daily dose, $\mathrm{mg}$ & - & 158 & 355,1 & 580 \\
& & {$[87,9 ; 307,7]$} & {$[138,5 ; 685,7]$} & {$[320 ; 1200]$} \\
NSAIDs intake index & 28,6 & 5,8 & 15,5 & 24,4 \\
& {$[16,7 ; 50]$} & {$[2,9 ; 11,8]$} & {$[4,7 ; 30,9]$} & {$[9,5 ; 50]$} \\
\hline
\end{tabular}

The index of NSAID intake in the first trim. was lower than before pregnancy and in the second half of gestation ( $p<0.05$ compared to the month of conception, II and III trim.). The average daily dose of ibuprofen was also lower in the first trim. than in the second and third trim. $(p<0.05)$, while the actual daily dose in the second trim. was higher than in the first and third trim. $(p<0.05$ in all cases).

There was no correlation between BASDAI AS activity, the level of nocturnal pain and the ibuprofen intake index, likewise the fact of NSAID withdrawal throughout pregnancy. In addition, there were no differences in BASDAI levels and back pain in women with a subjective need for NSAIDs, who did and did't take ibuprofen. $50 \%$ of women were committed to NSAID therapy in the first trim., $43.5 \%$ in the second trim., and $67.4 \%$ in the third trim. In pts with non-adherence to NSAID therapy, the BASDAI level was higher than in those who followed the recommendations of the rheumatologist throughout pregnancy: in the first trim. $-3.8[3.4$ 4.7] and $1.7[0.8 ; 2.2]$; in the second trim. - 3[2.3; 4.6] and $1.4[0.8 ; 2.7]$; in the 